\title{
Occurrence of Depression in Families with Frontotemporal Dementia: A Family History Study
}

\author{
V. Horstmann ${ }^{a}$ A. Gräsbeck ${ }^{b, c}$ \\ Departments of a Health Sciences and ${ }^{\mathrm{b}}$ Psychogeriatrics and ${ }^{\mathrm{c} S w e d i s h}$ National Institute of Health Care and \\ Sciences, Lund University, Lund, Sweden
}

\section{Key Words}

Frontotemporal dementia - Depression - Co-aggregation • Family history study

\begin{abstract}
Background: There are clinical similarities between frontotemporal dementia (FTD) and depression. The aim is to study co-aggregation of depression in families with FTD, indicating the existence of common aetiological factors. Methods: The study included 74 index patients with FTD and their 540 first-degree relatives above the age of 15 years. Occurrence of depression was studied at 3 different levels. Results: The incidence of depression in first-degree relatives of FTD patients was not higher than that of a general population. Occurrence of depression was not higher in families where parents had FTD compared to families with parents having no indications of FTD. Individuals with FTD had not suffered from depression to a greater extent than those without FTD. Conclusions: The hypothesis of a common aetiological factor of FTD and depression was not supported.
\end{abstract}

Copyright ๑ 2009 S. Karger AG, Basel

\section{Introduction}

Frontotemporal dementia (FTD) constitutes $3-10 \%$ of all dementias in clinical and population studies. The clinical picture of FTD includes personality change, psychiatric symptoms, neurological and language-expressive deficits, mainly reflecting the pathological involvement of the frontal and anterior temporal lobes. In familial cases of FTD, genetic analyses have shown linkage to disease loci on chromosomes $3,9,16$, and 17. On chromosome 17, several mutations have been identified. However, in the majority of sporadic as well as familial cases, the cause is still unknown [1-8].

FTD has certain clinical similarities with depression, which makes the diseases difficult to distinguish from each other, particularly early in the course. Psychiatric symptoms, such as depressiveness, suicidal ideation, apathy, anxiety and amimia occur in both FTD and depression. FTD and depression can show signs of frontal dysfunction on regional cerebral blood flow, MRI, and neuropsychological tests [9-18].

Furthermore, like FTD, depression runs in families, and genes are known to be aetiologically involved. However, these genes have not been fully identified, nor has the nature of their involvement $[19,20]$. 
Table 1. Demographic characteristics of 74 families $(n=614)$ with FTD

\begin{tabular}{lrl}
\hline First-degree relatives & $\mathrm{n}$ & Age, years \\
\hline Index patients & & \\
$\quad$ Alive & 15 & $70(51-80)$ \\
$\quad$ Deceased & 59 & $69(38-88)$ \\
Parents & & \\
$\quad$ Alive & 9 & $80(58-92)$ \\
$\quad$ Deceased & 135 & $85(29-99)$ \\
Siblings & & \\
$\quad$ Alive & 135 & $70(33-93)$ \\
$\quad$ Deceased & 113 & $69(15-92)$ \\
Children & & \\
$\quad$ Alive & 147 & $46(21-70)$ \\
$\quad$ Deceased & 1 & 57 \\
\hline
\end{tabular}

Ages taken at death for deceased relatives and at interview for those still alive, and presented as medians with ranges in parentheses.

The aim of the present study was to search for indications supporting the theory of a shared aetiology of FTD and depression. This was done by studying the occurrence of depression in families with FTD in 3 different ways.

\section{Materials and Methods}

\section{Family Members}

The present study has been approved by the Local Ethics Committee at Lund University.

The index patients of the present study originate from a reevaluation of 253 patients with frontotemporal dysfunction, examined at the Department of Psychiatry and Psychogeriatrics in Lund 1967-1999. At re-evaluation, 97 of these 253 patients fulfilled the criteria of FTD according to the clinical ICD-10 criteria of dementia in Pick's disease [21] and the Lund-Manchester criteria [1]. By 23 November 2000, 74 of the 97 patients had died. Forty-four of the 74 deceased patients were autopsied, and all of them were verified neuropathologically as FTD according to the Lund-Manchester criteria [1]. For a comprehensive description of the patients, see Gräsbeck et al. [22]. The 97 patients with FTD included 10 patients from 3 pedigrees. One patient from each of these pedigrees was chosen as the index patient. The remaining 7 patients were withdrawn from the original patient sample and included as relatives, leaving 90 patients as index cases.

A family history study was performed according to the instructions of Endicott et al. [23]. In this type of study, 1 informant of each index patient's family gives information about diseases of the index patient and his/her first-degree relatives. A genealogy expert collected the identity, date of birth, and eventual date of death of the first-degree relatives from official registers.
We contacted those informants who were well acquainted with the patient and the staff of the department. If such informants were deceased, could not be reached, or had limited knowledge of the family, another informant was contacted.

Informed consent was obtained from 74 of 90 possible informants. In 59 families, 1 informant was interviewed. In 15 families, 1 or 2 additional informants gave supplementary information.

In total, there were 638 first-degree relatives of the 74 participating families. Those relatives who died before the age of 15 years or had not reached that age at the date of the interview were excluded in the present study. This resulted in 614 family members, including 74 index patients and 540 first-degree relatives (302 men and 312 women). The median size of these 74 families was 8 individuals (range 3-19). Their demographic characteristics are presented in table 1.

For 16 of the 90 index cases, it was not possible to obtain informants. The reasons were: no living relative was found (3 cases), relatives did not answer to invitation letters repeatedly sent to them (4 cases), 9 informants did not wish to participate, and 1 family had emigrated. In all, there were 103 members in the dropout families. The median size of these 16 families, including all ages, was 7 individuals (range 3-14).

\section{Family History Interview}

The interviews took place in the year 2001, except for 1 family whose informant was interviewed in 2003. The interviews were performed in accordance with the guidelines of the Family History Research Diagnostic Criteria (FH-RDC) [23, 24]. The senile organic brain syndrome criteria were supplemented with items from 3 diagnostic rating scales for recognition of Alzheimer's disease, FTD and vascular dementia [25], and from a family history questionnaire of dementia [26]. The informants were interviewed mostly by telephone, by either the research nurse Karin Nilsson (K.N.) or the medical doctor Helena Sjöström (H.S.), both specialized in geriatric psychiatry.

\section{Diagnostics}

The evaluators of the interviews (K.N., H.S., or medical doctor Martin Sjöbeck) were not informed about the aim of the study. All available information, including data from interviews, medical records, death certificates and autopsy reports, was used in the evaluation. In case of difficulties, diagnosis was established through consensus discussion with other investigators.

The diagnosis of FTD was made according to the Lund-Manchester consensus [1] and the ICD-10 criteria of dementia in Pick's disease [21].

The diagnosis of depression was evaluated according to the diagnostic guidelines of the FH-RDC [23]. In the present study, cases with bipolar disorder were included in the category depression.

Cases were coded in the following way: a positive diagnosis of the disorder in question (coded as 'yes') was made when the individuals met the diagnostic criteria completely. When there were indications of a disorder but not sufficient information to reach a diagnosis, cases were coded as 'probable'. If there was sufficient information to negate the diagnosis, the individual was coded as 'no' (healthy). The remaining individuals were coded as 'unknown'.

One limitation of the family history method is the expected large amount of false-negative cases; therefore, the probable cases 
were included into the positive ones in all the calculations [27]. This resulted in 3 groups for each of the diseases; ill cases (yes/ probable), healthy cases (no), and cases with lack of information for a diagnosis (unknown).

\section{Occurrence of Depression}

In an earlier study, first-degree relatives of index patients with FTD were found to have a higher incidence of FTD compared to that of a general population, indicating a familial aggregation of FTD due to genetic and/or shared environmental factors. We now investigated if an increased incidence of depression could also be found among the relatives. A positive finding indicates shared familial factors. The comparison population was taken from the Lundby Study of mental health, a cohort study including all inhabitants in a geographically defined area in southern Sweden [28]. The participants were investigated in person by psychiatrists in 1947, 1957, 1972, and finally in 1997; in particular, the diagnosis of depression was similar to that used in the FH-RDC.

A common determinant of FTD and depression could still be suspected even if the observed incidence of depression in the group of relatives was not higher than expected. This would be the case if depression and FTD tended to occur in the same families. We therefore compared the familial scores of depression in 2 groups of families; 1 group, where at least 1 of the index patient's parents had FTD, and another, with no indications of FTD in the parents. Higher scores of depression were expected in the group of families with at least 1 parent having FTD.

Finally, we studied whether individuals with FTD had suffered from depression to a greater extent than those who had not developed FTD.

\section{Statistical Methods}

The age- and sex-specific incidences of depression were calculated for the group of first-degree relatives of the 74 index patients with FTD. Of the 540 first-degree relatives, 90 were excluded because of lack of information for a diagnosis. Another 10 relatives diagnosed with depression were excluded since no information on age at onset of the disorder could be obtained. Hence, the analyses included 440 relatives ( 217 men and 223 women). The risk period started at the age of 15 years, and lasted until the date the person contracted a depression, died, or until the date of the interview, whichever occurred first. Comparisons were made with the incidence rates of depression in the Lundby Study, calculated on 1,312 men and 1,238 women for the period 1947-1972 [28].

Based on the evaluation of FTD of the index patients' parents, all families were divided into 2 groups: 1 group of families where at least 1 parent had FTD and another group of families with no indications of FTD. No indication of FTD means that the parent was evaluated as either healthy with regard to FTD (no), or that information for a diagnosis of FTD was lacking (unknown).

Among all 614 family members, those 97 who were rated as unknown with regard to the diagnosis of depression were excluded, resulting in 517 family members. The group where FTD was present in the index patients' parents included 11 families with 78 individuals, and the other group included 63 families with 439 individuals.

The proportions of cases with depression in each of the groups of relatives were calculated.

However, when testing for a difference between the groups regarding depression it has to be acknowledged that members of the
Table 2. Diagnostic evaluation of the 74 families with FTD ( $\mathrm{n}=$ 614)

\begin{tabular}{|c|c|c|c|c|c|c|c|}
\hline & \multicolumn{3}{|c|}{ FTD } & \multicolumn{3}{|c|}{ Depression } & \multirow{2}{*}{$\begin{array}{l}\text { To- } \\
\text { tal }\end{array}$} \\
\hline & ill & health & unknown & ill & healtl & unknown & \\
\hline Index patients & 74 & - & - & 6 & 61 & 7 & 74 \\
\hline Parents & 11 & 111 & 22 & 16 & 116 & 12 & 144 \\
\hline Siblings & 15 & 165 & 68 & 21 & 156 & 71 & 248 \\
\hline Children & - & 142 & 6 & 18 & 123 & 7 & 148 \\
\hline Total & 100 & 418 & 96 & 61 & 456 & 97 & 614 \\
\hline
\end{tabular}

same family are not independent with regard to diagnosis. Hence, for each family, a score of depression was calculated as the proportion of ill cases. The difference was tested by means of the MannWhitney U test.

Finally, we studied if individuals with FTD had suffered from depression to a greater extent than relatives without FTD. Individuals that had died before the age of 40 years or had not reached that age at the interview date were excluded, as were those rated as unknown with regard to FTD and/or depression. This resulted in 443 persons with or without FTD that were studied with regard to earlier depression using cross-tabulation. The same procedure was repeated for those aged 50,60, and 70 years, respectively. The dependence between the diseases was tested by means of the $\chi^{2}$ test.

\section{Results}

Table 2 shows the diagnostic evaluation of FTD and depression in the 614 family members. There were 100 (88 yes/12 probable) cases diagnosed with FTD according to the clinical Lund-Manchester criteria. Sixty-one family members (39 yes/22 probable) had suffered from depression according to FH-RDC. Four of these cases had a bipolar disorder.

Table 3 presents the age- and sex-specific incidence rates of depression in 440 first-degree relatives (217 men and 223 women) of the index patients with FTD. Twentythree men and 22 women had suffered from depression. There was no difference between the male and female age-specific incidence rates.

Figure 1 shows that the incidence rates of depression in the male and female relatives of index patients with FTD were not higher compared to the corresponding rates of the Lundby study. There were differences with regard to gender and age at onset in the 2 studies. While the male and female relatives of FTD patients had similar rates of depression, women had higher rates than men in the Lundby study. In the relatives of FTD patients, there 
Fig. 1. Age-specific incidences of depression in first-degree relatives of FTD patients and in the Lundby Study.

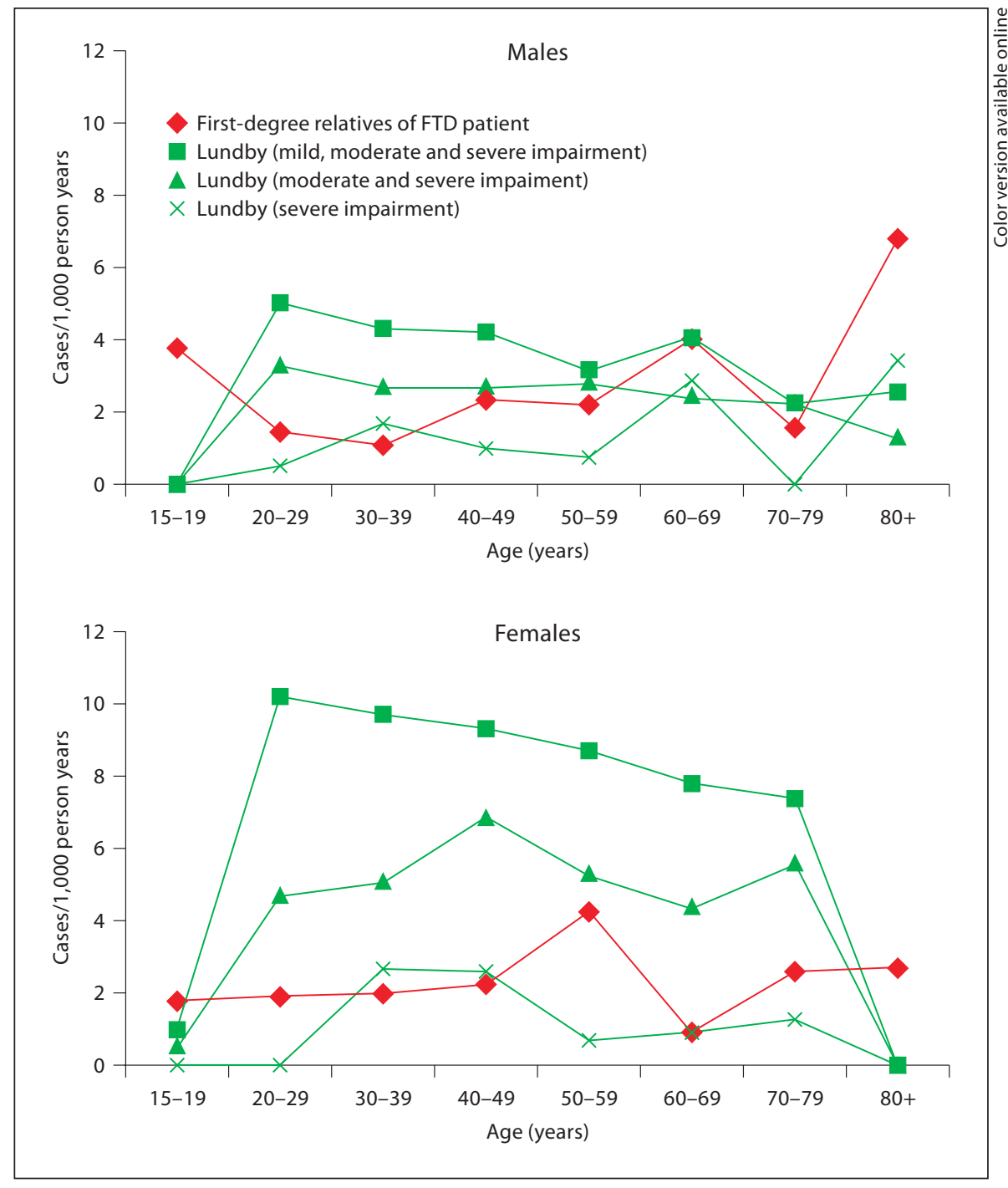

was a tendency towards an older age at onset that was most pronounced in men; in the Lundby study, most men and women developed their first episode of depression before the age of 50 years.

There were 8 cases with depression ( $10 \%$ of the 78 family members) in the group of families where index patients' parents had FTD. Fifty-three cases had suffered from depression ( $11 \%$ of the 439 family members) in the group of families with index patients' parents with no indications of FTD.

Figure 2 shows the distribution of the familial scores of depression in the 2 groups. There was no difference between the 2 groups with regard to familial scores of depression $(\mathrm{p}=0.94)$.
Table 3. Incidence of depression in 440 first-degree relatives of 74 index patients with FTD

\begin{tabular}{|c|c|c|c|c|c|c|}
\hline \multirow[t]{2}{*}{$\begin{array}{l}\text { Age } \\
\text { years }\end{array}$} & \multicolumn{2}{|c|}{ Person years } & \multicolumn{2}{|c|}{ Cases } & \multicolumn{2}{|c|}{$\begin{array}{l}\text { Cases per } \\
1,000 \text { person years }\end{array}$} \\
\hline & male & female & male & female & male & female \\
\hline $15-19$ & 1,065 & 1,110 & 4 & 2 & 3.75 & 1.80 \\
\hline $20-29$ & 2,044 & 2,147 & 3 & 2 & 1.47 & 0.93 \\
\hline $30-39$ & 1,911 & 1,981 & 2 & 4 & 1.05 & 2.02 \\
\hline $40-49$ & 1,706 & 1,770 & 4 & 4 & 2.35 & 2.26 \\
\hline $50-59$ & 1,363 & 1,409 & 3 & 6 & 2.20 & 4.26 \\
\hline $60-69$ & 985 & 1,178 & 4 & 1 & 4.06 & 0.85 \\
\hline $70-79$ & 646 & 775 & 1 & 2 & 1.55 & 2.58 \\
\hline $80-$ & 295 & 368 & 2 & 1 & 6.80 & 2.72 \\
\hline
\end{tabular}

Neuroepidemiology 2009;33:124-130 
Out of the 443 family members aged 40 years and over with sufficient information for a diagnostic evaluation of FTD and/or depression, 87 had developed FTD. Nine percent (8) of these had suffered from earlier depression. Of those 356 without FTD, there were 13\% (47) with an earlier episode of depression (table 4). Thus, depression was not more common in family members with FTD than in those who did not develop FTD $\left[\chi^{2}(1)=1.03, p=0.31\right]$. When the calculations were restricted to individuals above 50, 60 and 70 years, the results were the similar.

\section{Discussion}

The hypothesis of shared aetiological factors in depression and FTD was based on similarities in clinical symptoms, psychological findings, brain imaging, and repeated findings that each of these diseases aggregates in families $[29,30]$. We investigated the hypothesis by analysing the occurrence of depression in 74 families with FTD.

A common familial aetiology in FTD and depression would imply an increased incidence of depression among the first-degree relatives of FTD patients compared to that in the general population. However, no such increase was found (fig. 1).

We also divided the families in 2 groups according to the evaluation of FTD in the index patient's parents; a higher occurrence of depression was expected in the families where a parent had FTD. However, when comparing the familial scores of depression in the 2 groups, there was no difference (fig. 2).

Finally, when individuals with and without FTD were compared with regard to occurrence of earlier depression, no difference was found (table 4).

Hence, in this study it was not possible to support the hypothesis of a common aetiological factor in FTD and depression. Instead, our findings indicate separate aetiologies. This is supported by the differences in the clinical picture in FTD and depression. The median age at onset of FTD is in the late 50s, although cases with onset in the early 20 s have been reported. The first onset of depression may occur in childhood or throughout life, though most cases have their debut before the age of 50 years. There are also differences in FTD and depression with regard to symptoms and course. The psychiatric symptoms of FTD are evasive, without further development into sustained depressive disorder. Furthermore, patients with FTD have severer cognitive deficits in special domains compared with cases with depression [3133]. The course of FTD is always progressive, while de-

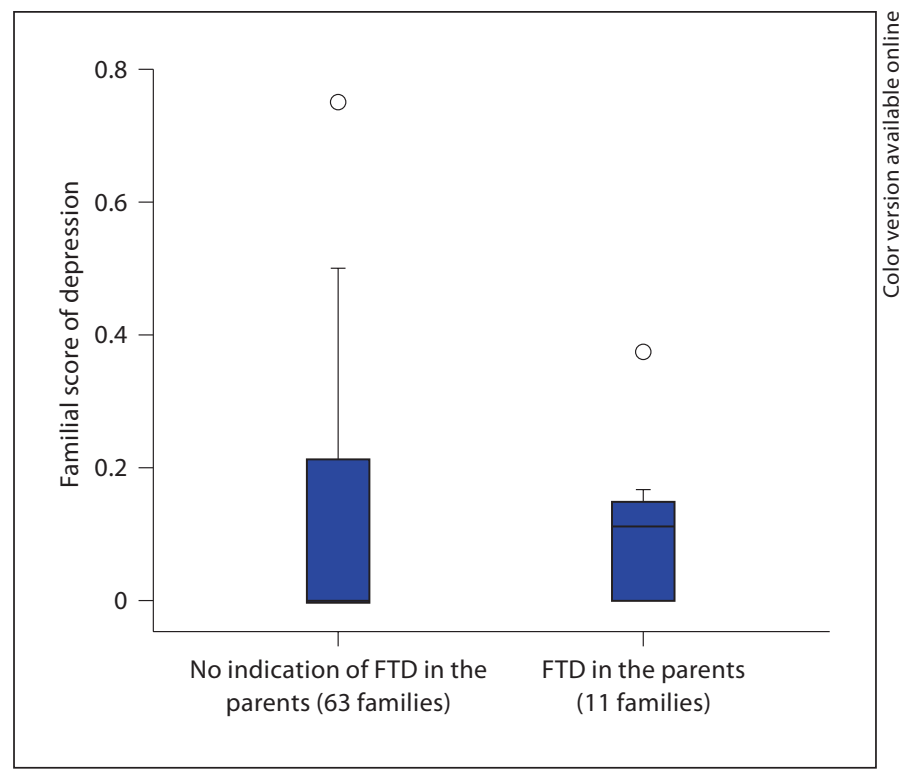

Fig. 2. Familial scores of depression in 2 groups of families.

Table 4. Prevalence of depression in 443 family members with or without FTD (aged 40 years or above)

\begin{tabular}{lccc}
\hline & FTD & No FTD & Total \\
\hline Depression & 8 & 47 & 55 \\
No depression & 79 & 309 & 388 \\
\hline Total & 87 & 356 & 443 \\
\hline \multicolumn{2}{c}{$\chi^{2}(1)=1.03, \mathrm{p}=0.31}$. & & \\
\hline
\end{tabular}

pression either remits or takes a chronic course $[25,34-$ 39].

An important limitation of the family history method is the underestimation of true cases [40].

In the present study, a genealogy expert from official registers, securing that all relatives were found, had identified the relatives. The interviews were conducted by specialists in geriatric psychiatry according to the instructions of FH-RDC. Informants, already well acquainted with the patient and the staff, were asked for predetermined specific criteria of broadly defined diagnoses for each relative. Relatives rated as probable were included among positive cases in order to avoid underestimation of cases, although there is a subsequent risk of having false-positive cases. 
The diagnostic accuracy would increase by increasing the number of informants. In the present study, 2 or more informants per family were used in about $20 \%$ of all families. The accuracy was increased by adding information from other sources, such as medical records, autopsy reports, and death certificates. Thus, 88 of 100 cases diagnosed with FTD had been clinically investigated in an extensive way according to the medical records. The diagnosis was confirmed neuropathologically in 44 cases.

In 15 of the 61 cases with depression, information was obtained from the psychiatric records at the time of treatment for depression. For another 9 persons, information about depression was derived from the index patients' medical records, and in additional 4 cases there was information about the treatment of depression in the family history interview, but the medical record could not be found.

It is known that the diagnostic accuracy is increased when the informant is interviewed at the same time as the relative is treated for the diagnosis in question [40]. This was far from possible in the present study. Another contributing factor to an underestimation of cases is the frequent lack of contact between informants and index patients' relatives throughout life. Furthermore, information about illness in relatives could have been lost because of impaired recall.

The incidence of depression in the first-degree relatives of FTD patients was surely under-estimated due to the 10 relatives that were excluded because of the lack of information regarding the onset age of depression. Contrary to what is often seen in the general population, male and female relatives of FTD patients had similar rates of depression. Light or moderate episodes of depression, more commonly found in women (fig. 1) [41], could easily have been missed.

There was no aggregation of depression, neither in the family group with parental FTD (fig. 2) nor in the group of individuals with FTD (table 4).

We have considered the possibility of unknowns being more prevalent in these groups.

The proportions of unknowns in the family group with parental FTD and in the family group without FTD were similar, nor was there any difference regarding the proportions of unknowns in the group of individuals with FTD compared to the group without FTD. This indicates that the family group with parental FTD and the group of individuals with FTD were no less scrutinized with regard to depression than the comparison groups without FTD.

In the present study, the size of the non-participating families was generally smaller than that of the participat- ing families. One obvious explanation to this is that families of a smaller size have fewer potential informants. However, a smaller size of family may also indicate illness. Due to the lack of specific information regarding diagnostic evaluation of FTD and depression, it is not possible to say how inclusion of these families would have influenced the result.

\section{Conclusions}

The theory of an aetiological association between depression and FTD was analysed in several ways, but could not be supported. However, because of limitations to the family history method and limited knowledge about the dropouts, the hypothesis cannot be totally ruled out.

\section{Acknowledgements}

This study was supported by the Swedish Research Council (No. 13071, 13249, 13071, 14217, 1350), the Swedish National Institute of Health Care and Sciences, Lund University, the Alzheimer Foundation, the Sjöbring Foundation, the O.M. Persson Foundation and the Clas Groschinsky Foundation. Special thanks to Prof. Lars Gustafson, Chair of the Dept. of Psychogeriatrics at the time when Anne Gräsbeck, PhD, MD, was employed and analysed the data. Further thanks to Karin Nilsson, PhD, research nurse, Martin Sjöbeck, PhD, MD, and Helena Sjöström, MD, from the Dept. of Psychogeriatrics, Prof. Ulf Kristofferson, Dept. of Clinical Genetics, Lund University, and Senior Archivist KjellOve Persson.

References Mann DMA, Neary D, Snowden J: Clinical and neuropathological criteria for frontotemporal dementia. The Lund and Manchester Groups. J Neurol Neurosurg Psychiatry 1994;57:416-418.

-2 Pasquier F, Delacourte A: Non-Alzheimer degenerative dementias. Curr Opin Neurol 1998:11:417-427.

- 3 Mann D, McDonagh A, Snowden JS, Neary D, Pickering-Brown SM: Molecular classification of the dementias. Lancet 2000;355: 626.

4 Poorkaj P, Grossman M, Steinbart E, Payami H, Sadovnick A, Nochlin D, Tabira T, Trojanowski JQ, Borson S, Galasko D, Reich S, Quinn B, Schellenberg G, Bird TD: Frequency of tau gene mutations in familial and sporadic cases of non-Alzheimer dementia. Arch Neurol 2001;58:351-352. 
5 Rosso SM, Donker Kaat L, Baks T, Joosse M, de Koning I, Pijnenburg Y, de Jong D, Dooijes D, Kamphorst W, Ravid R, Niermeijer MF, Verheij F, Kremer HP, Scheltens P, van Duijn CM, Heutnik P, van Swieten JC: Frontotemporal dementia in the Netherlands: patient characteristics and prevalence estimates from a population-based study. Brain 2003; 126:2016-2022.

6 Ruddy DM, Parton MJ, Al-Chalabi A, Lewis CM, Vance C, Smith BN, Leigh PN, Powell JF, Siddique T, Meyles EP, Baas F, De Jong V, Shaw CE: Two families with familial amyotrophic lateral sclerosis are linked to a novel locus on chromosome 16q. Am J Hum Genet 2003;73:390-396.

7 Baker M, Mackenzie IR, Pickering-Brown SM, Gass J, Rademakers R, Lindholm C, Snowden J, Adamson J, Sadovnick SD, Rollinson S, Cannon A, Dwosh E, Neary D, Meluist S, Richardson A, Dickson D, Berger Z, Eriksen J, Robinson T, Zehr C, Dickey CA, Crool R, McGowan E, Mann D, Boeve B, Feldman H, Hutton M: Mutations in progranulin cause tau-negative frontotemporal dementia linked to chromosome 17. Nature 2006;15:2988-3001.

8 Cruts M, Gijselinck I, van der Zee J, Engelborghs S, Wils H, Pirici D, Rademakers R, Vandenberghe R, Dermaut B, Martin J, van Duijn C, Peeters K, Sciot R, Santens P, De Pooter T, Mattheijssens M, Van den Broeck M, Cuijt I, Vennekens K, De Deyn PP, KumarSingh S, Van Broeckhoven C: Null mutations in progranulin cause ubiquitin-positive frontotemporal dementia linked to chromosome 17q21. Nature 2006;19:666-888.

$\checkmark 9$ Simone F, Valerio P, Labella A, Felici F: Juvenile Pick's disease: a clinical study. Riv Neurol 1975;45:399-417.

$>10$ Miller BL, Cummings JL, VIllanueva-Meyer J, Boone K, Mehringer CM, Lesser IM, Mena I: Frontal lobe degeneration: clinical, neuropsychological, and SPECT characteristics. Neurology 1991;41:1374-1382.

$\checkmark 11$ Gregory CA, Hodges JR: Frontotemporal dementia: use of consensus criteria and prevalence of psychiatric features. Neuropsychiatr Neuropsychol Behav Neurol 1996;9:145153.

12 Damasio AR: Neuropsychology: towards a neuropathology of emotion and mood. Nature 1997;386:769-770.

-13 Risberg J, Gustafson L: Regional cerebral blood flow measurements in the clinical evaluation of demented patients. Dem Geriatr Cogn Dis 1997;8:92-97.

-14 Suzuki H, Kuroda S, Ishizu H, Fujisawa Y, Sasaki K: Depression in the early stages of Pick's disease. Acta Med Okayama 1999;53: 253-257.

-15 Larsson EM, Passant U, Sundgren PC, Englund E, Brun A, Lindgren A, Gustafson L: Magnetic resonance imaging and histopathology in frontotemporal dementia. Dement Geriatr Cogn Disord 2000;11:123134.
6 Landro NI, Stiles TC, Sletvold H: Neuropsychological function in nonpsychotic unipolar major depression. Neuropsychiatr Neuropsychol Behav Neurol 2001;14:233-240.

17 Baudic S, Tzortzis C, Barba GD, Traykov L: Executive deficits in elderly patients with major unipolar depression. J Geriatr Psychiatry Neurol 2004;17:195-201.

18 Weiland-Fiedler P, Erickson P, Waldeck T, Luckenbaugh DA, Pike D, Bonne O, Charney DS, Neumeister A: Evidence for continuing neuropsychological impairments in depression. J Affect Disord 2004;82:253-258.

19 Hudson JI, Mangweth B, Harrison G, Pope HG Jr, De Col C, Hausman A, Gutweniger MA, Laird NM, Biebl W, Tsuang MT: Family study of affective spectrum disorder. Arch Gen Psychiatry 2003;60:170-177.

20 Hasler G, Drevets WC, Manji HK, Charney DS: Discovering endophenotypes for major depression. Neuropsychopharmacology 2004;29:1765-1781.

21 World Health Organisation: International Statistical Classification of Diseases and Related Health Problems, ed 10. Geneva, WHO, 1992.

22 Gräsbeck A, Horstmann V, Englund B, Passant U, Gustafson L: Evaluation of Predictors of mortality in clinically diagnosed frontotemporal dementia. Int J Geriatr Psychiatry 2003;18:586-593.

23 Endicott J, Andreasen N, Spitzer RL: Family History-Research Diagnostic Criteria. New York, New York State Psychiatric Institute, 1975.

24 Andreasen N, Endicott J, Spitzer L, Winokur G: The family history method using diagnostic criteria: reliability and validity. Arch Gen Psychiatr 1977;34:1229-1235.

25 Brun A, Gustafson L: The Lund Longitudinal Dementia Study: a 25-year perspective on neuropathology, differential diagnosis and treatment; in Corain B, Nicolini $M$, Winblad B, Wisniewski H, Zatta P (eds): Alzheimer's Disease: Advance in Clinical and Basic Research. New York, John Wiley \& Sons, 1993, pp 4-18.

26 Barber R, Snowden JS, Craufurd D: Frontotemporal dementia and Alzheimer's disease: retrospective differentiation using information from informants. J Neurol Neurosurg Psychiatry 1995;59:61-70.

-27 Gräsbeck A, Horstmann V, Nilsson K, Sjöbeck M, Sjöström H, Gustafson L: Dementia in first-degree relatives of patients with frontotemporal dementia (FTD) - a family history study. Dement Geriatr Cogn Disord 2005;19:145-153.

28 Hagnell O, Lanke J, Öjesjö L, Rorsman B: The Incidence of Mental Illness over a Quarter of a Century. Stockholm, Almqvist \& Wicksell, 1990.
29 Kendler KS, Davis CG, Kessler RC: The familial aggregation of common psychiatric and substance use disorders in the National Comorbidity Survey: a family history study. Br J Psychiatry 1997;170:541-548.

30 Gustafson L: Frontal lobe degeneration of non-Alzheimer type. II. Clinical picture and differential diagnosis. Arch Gerontol Geriatr 1987;6:209-223.

31 Gregory CA: Frontal variant of frontotemporal dementia: a cross-sectional and longitudinal study of neuropsychiatric features. Psychol Med1999;29:1205-1217.

32 Elderkin-Thompson V, Boone KB, Hwang S, Kumar A: Neurocognitive profiles in elderly patients with frontotemporal degeneration or major depressive disorder. J Int Neuropsychol Soc 2004;10:753-771.

33 Neary D, Snowden JS, Gustafson L, Passant U, Stuss D, Black S, Freedman M, Kertesz A, Robert PH, Albert M, Boone K, Miller BL, Cummings J, Benson DF: Frontotemporal lobar degeneration: a consensus on clinical diagnostic criteria. Neurology 1998;51: 1546-1554.

-34 Solomon DA, Keller MB, Leon AC, Mueller TI, Lavori PW, Shea MT, Coryell W, Warshaw M, Turvey C, Maser JD, Endicott J: Multiple recurrences of major depressive disorder. Am J Psychiatry 2000;157:229-233.

-35 McKhann GM, Albert MS, Grossman M, Miller B, Dickson D, Trojanowski JQ: Clinical and pathological diagnosis of frontotemporal dementia: report of the Work Group on Frontotemporal Dementia and Pick's Disease. Arch Neurol 2001;58:1803-1809.

36 Gräsbeck A, Englund B, Horstmann V, Passant U, Gustafson L: Predictors of mortality in clinically diagnosed frontotemporal dementia. Int J Geriatr Psychiatry 2003;8:594601 .

37 Kessing LV: Course of illness in depressive and bipolar disorders. Br J Psychiatry 2004; 185:372-377.

38 Snowden JS, Neary D, Mann DM: Autopsy proven sporadic frontotemporal dementia due to microvacuolar-type histology, with onset at 21 years of age. J Neurol Neurosurg Psychiatry 2004;75:1337-1339.

39 Faraone SV, Tsuang MT: Methods in psychiatric genetics; in Tsuang MT, Tohen M, Zahner GEP (eds): Textbook in Psychiatric Epidemiology. New York, John Wiley \& Sons, 1995, pp 81-134.

40 Andreasen N, Rice J, Endicott J, Reich T, Coryell $\mathrm{W}$ : The family history approach to diagnosis: how useful is it? Arch Gen Psychiatr 1986;43:421-429.

41 Rorsman B, Gräsbeck A, Hagnell O, Lanke J, Öhman R, Öjesjö L, Otterbeck L: A prospective study of first incidence depression. The Lundby Study. Br J Psychiatry 1990;156:336342 . 